\author{
Universidade de São Paulo \\ Faculdade de Medicina de Ribeirão Preto \\ Departamento de Patologia
}

Efeitos do uso do Orlistat na proliferação celular da mucosa colônica e na formação de focos de criptas aberrantes induzidos por Dimetilhidrazina em ratos

Ribeirão Preto 


\section{Efeitos do uso do Orlistat na proliferação celular da mucosa colônica e na formação de focos de criptas aberrantes induzidos por Dimetilhidrazina em ratos}

Tese apresentada ao programa de pós-graduação da Faculdade de Medicina de Ribeirão Preto da Universidade de São Paulo. Área de Concentração: Patologia. Sub-área: Patologia Experimental, para obtenção do título de Mestre.

Orientador : Prof. Dr. Sérgio Britto Garcia

Ribeirão Preto 
Este trabalho foi realizado no laboratório de Patologia do Departamento de Patologia da Faculdade de Medicina de Ribeirão Preto da Universidade de São Paulo e contou com o apoio financeiro da Coordenação de Pessoal de Nível Superior (CAPES). 


\section{Dedicatória}

A DEUS, por sempre me mostrar o caminho.

A meus pais, Esmeraldo Abreu de Barros e Edna da Costa Barros pelo esforço, dedicação e constante presença em todos os passos da minha vida e exemplo de trabalho, honestidade e determinação.

Aos meus irmãos Luciano e Luciana, meus cunhados Klayton e Rita e sobrinhos Bruno, Kyara, Lucas e Felipe pelo carinho.

A Cícero Pereira Viana, pelo apoio e confiança. 


\section{Agradecimento especial}

Ao Prof. Dr. Sérgio Britto Garcia, pela amizade, orientação e demonstração de confiança, especialmente pelos conhecimentos transmitidos.

A Rosangela Orlandin Lopes e família.

A essas pessoas, muito importantes para mim, que me ensinaram o valor da verdadeira amizade, sou eternamente grata pelo carinho, apoio, preocupação e sinceridade. Sem vocês, seria muito difícil a conclusão da minha pós-graduação. 


\section{Agradecimentos}

A todos os colegas de pós-graduação: Patrícia Modiano, Aline Turatti, Marcelo Vespúcio,

Marcelo Demarzo pela amizade, colaboração, incentivo e companheirismo.

A Neide Terezinha Gonçalves, pelo apoio, amizade e confiança sempre.

Aos funcionários da secretaria do Departamento de Patologia da FMRP-USP, Rosângela Paiva, Daniel Barcelini, Antônio de Pádua e Lucyara Santana, pela demonstração de amizade e apoio na realização deste trabalho.

Aos amigos Carlos Eduardo D’Angelis, Marcela Hassumi, Andriele Fernandes, Paulo Quemelo, Márcia Guimarães, Cleverson Rodrigues, Flávia Martinelo, Fernando Costa, Luiz Fernando Martin, Deise Lúcia, Auristela Martins e Maria Aparecida.

A minha nova e eterna família Araguarina Moacir Rômulo Ozório de Paiva, Cleuza Paiva, Juliana, Simone e Luciana; Tania Mara dos Santos, Jamilla e Gustavo.

A Vitor Malta pela confiança e carinho.

A todos aqueles que, direta ou indiretamente, contribuíram pela inestimável colaboração na realização deste trabalho. 


\section{Sumário}

ABREVIATURAS

RESUMO

ABSTRACT

1. INTRODUÇÃO

1.1 - Câncer colorretal 2

1.2 - Carcinogênese colorretal 2

1.3 - Alimentação, nutrição e câncer 5

$\begin{array}{ll}1.4 \text { - O Orlistat } & 7\end{array}$

1.5 - Modelo experimental de carcinogênese química pela Dimetilhidrazina 8

1.6 - Biomarcadores da carcinogênese colônica 10

$\begin{array}{ll}\text { 1.6.1 - Focos de criptas aberrantes } & 10\end{array}$

1.6.2 - A proliferação celular epitelial durante as etapas da carcinogênese 13

2 - JUSTIFICATIVA 16

$\begin{array}{lr}3 \text { - OBJETIVOS } & 18\end{array}$

4 - MATERIAL E MÉTODOS $\quad 20$

$\begin{array}{ll}4.1 \text { - Animais } & 21\end{array}$

4.2 - Preparação da ração $\quad 22$

4.3 - Delineamento experimental 23

4.4 - Imunoistoquímica e morfometria 24

4.5 - Indução de lesões pré-neoplásicas em mucosa colônica 25

$\begin{array}{ll}4.6 \text { - Preparo do carcinógeno } & 25\end{array}$ 
$\begin{array}{ll}4.7 \text { - Segurança para a DMH } & 25\end{array}$

$\begin{array}{ll}4.8 \text { - Aplicação do carcinógeno } & 26\end{array}$

4.9 - Sacrifício do animal 26

$\begin{array}{ll}4.10 \text { - Coleta e processamento do cólon } & 27\end{array}$

$\begin{array}{ll}4.11 \text { - Análise histológica } & 28\end{array}$

4.12 - Proliferação celular epitelial $\quad 28$

4.13 - Avaliação dos focos de cripta aberrante 30

$\begin{array}{ll}4.14 \text { - Análise estatística } & 30\end{array}$

5 - RESULTADOS 31

6 - DISCUSSÃO 36

7 - CONCLUSÕES 41

8 - REFERÊNCIAS BIBLIOGRÁFICAS 43 


\section{Lista de abreviaturas}

FCAs Focos de criptas aberrantes

DMH Dimetilhidrazina

CC Carcinogênese colônica

CCR Câncer colorretal

COX-2 Ciclo-oxigenase 2

PCNA Proliferating Cell Nuclear Antigen 


\section{RESUMO}


O Orlistat é um membro de uma classe de drogas usadas como tratamento para obesidade. No entanto, a segurança de seu uso em longo prazo ainda não é conhecida. O Orlistat exerce sua atividade no lúmen do trato gastrintestinal inibindo a enzima lipase pancreática, responsável pela hidrólise dos triacilglicerídeos normalmente ingeridos com a dieta. Esse medicamento, quimicamente sintetizado, é um derivado da lipstatina, inibidora natural da lipase produzida pelo Streptomyces toxytricini. Assim, a excreção de gordura fecal fica significativamente aumentada com o uso do Orlistat. Estudos epidemiológicos e em modelos experimentais, sugerem que o aumento das dietas hipergordurosas tem efeito promotor para o câncer colorretal. Tal efeito deve ser relacionado, pelo menos parcialmente, às mudanças intra-colônicas causadas pela ação direta da gordura nas células da mucosa do cólon, os colonócitos. O estudo atual tem como objetivo verificar os efeitos do Orlistat na formação colônica de focos de criptas aberrantes (FCA) e na proliferação celular epitelial da mucosa gastrintestinal.

Ratos Wistar machos receberam dieta padrão ou dieta com aumento de gordura, suplementada ou não com Orlistat (200 mg/kg), e duas doses semanais do carcinógeno químico Dimetilhidrazina $(\mathrm{DMH})(25 \mathrm{mg} / \mathrm{kg})$. Após 30 dias, nos animais tratados com DMH, o Orlistat foi associado a um aumento significativo no número de FCAs colônicos e na proliferação celular epitelial da mucosa do cólon, independentemente da dieta. Os achados obtidos neste trabalho permitem concluir que o aumento do teor de gordura na luz do cólon distal, em decorrência da ação do Orlistat, pode potencializar a ação da DMH na formação de FCAs e no aumento da proliferação celular epitelial da mucosa colônica.

Palavras-chave: Orlistat, carcinogênese colônica, focos de criptas aberrantes, PCNA. 


\section{Abstract}


Orlistat is a member of a drug class used as obesity treatment. However, the security of its use in a long period of time is not known yet. Orlistat has its activity in the lumen of the gastrointestinal tract inhibiting the pancreatic lipase enzyme responsible for the hydrolyze of the triglycerides that usually are swallowed with the diet. This drug chemically synthesized, is a derived from lipstatina, that inhibit naturally the lipase produced by Streptomyces Toxytricini. So, the excretion of fat excrement stays significantly increased with the use of Orlistat. Epidemiologic studies and in experimental pattern, suggest that the increase of the high-fat diets facilitate the appearance of the colorectal cancer. Such effect must be related, at least partially to the changes intracolonic caused by the direct action of the fat in the cells of the colon mucous, the colonocytes. The current study has as objective to check the effects of the Orlistat on the formation of rat colonic aberrant crypt foci (ACF) and in the epithelial cell proliferation of the gastrointestinal mucous.

Male Wistar rats received either a standard diet or a high fat diet (HFD), supplemented or not with Orlistat $(200 \mathrm{mg} / \mathrm{kg}$ chow $)$ and two doses of the carcinogen dimethyl-hydrazine $(25 \mathrm{mg} / \mathrm{Kg})$. After 30 days, Orlistat was associated to a significant increase in the number of colonic ACFs and cell proliferation in $\mathrm{DMH}$-treated animals, independently of the HFD. The find got in this study permit to conclude that the increase in the level of adiposity inside the distal colon, due to Orlistat action, can potencializar the $\mathrm{DMH}$ action in the formation of ACFs and in the increase of epithelial cell proliferation of the colônica mucous.

Key-words: Orlistat, Carcinogenesis colonic, aberrant crypt foci, PCNA. 
1. INTRODUÇÃO 



\subsection{Câncer colorretal}

Estimativas para o ano de 2006 no Brasil apontam o câncer colorretal (CCR) como o $5^{\circ}$ tumor maligno mais freqüente entre os homens (com 11.390 casos novos) e $4^{\circ}$ entre as mulheres (com 13.970 casos novos). Estes valores correspondem a um risco estimado de 12 casos novos a cada 100 mil homens e 15 para cada 100 mil mulheres. A maior incidência de casos ocorre na faixa etária entre 50 e 70 anos, mas as possibilidades de desenvolvimento da doença já aumentam a partir dos 40 anos. Sem considerar os tumores de pele não melanoma, o câncer de cólon e reto em homens é o quarto mais freqüente nas regiões Sul (22/100.000), Sudeste (17/100.000) e CentroOeste (10/100.000). Nas regiões Nordeste (4/100.000) e Norte (3/100.000), ocupam a quinta e sexta posição, respectivamente. Para as mulheres é o segundo mais freqüente (21/100.000) na região Sudeste, o terceiro nas regiões Sul (22/100.000), Centro-Oeste (10/100.000) e Nordeste (5/100.000), enquanto na região Norte (4/100.000) ocupa a quinta posição

No mundo, os tumores malignos que acometem o cólon e o reto a cada ano somam cerca de 945 mil casos novos, sendo a quarta causa mais comum de câncer no mundo e a segunda em países desenvolvidos (INCA, 2006).

\subsection{Carcinogênese colorretal}

A carcinogênese é um processo presumivelmente complexo, onde ocorrem eventos celulares, moleculares e morfológicos (BIRD, 1995; FODDE, 2002). 
Desde a década de 40, vários pesquisadores estudaram o processo de carcinogênese e demonstraram a existência de três estágios. No primeiro, chamado de "iniciação", as células sofrem o efeito dos agentes cancerígenos ou carcinógenos, que provocam modificações permanentes e irreversíveis em alguns genes, como mutações simples, amplificações gênicas, rearranjos cromossômicos, translocações, deleções e aneuploidias (PITOT, 1993; ANDERSON, 1995).

Além das alterações citadas, a expressão dos genes pode ser alterada permanentemente pela exposição a alguns agentes. Nesse estágio, as células encontram-se geneticamente alteradas, não sendo possível ainda a detecção clínica do tumor. Elas encontram-se "preparadas" ou "iniciadas" para a ação de um segundo grupo de agentes, que atuará na etapa seguinte, e adquirindo maior capacidade de expansão clonal, quando comparadas com as vizinhas normais (HARRIS, 1991). A eficiência da iniciação depende da síntese do DNA e da divisão celular (ISHIKAWA et al., 1980).

O segundo estágio, denominado "promoção", proporciona a expressão fenotípica da alteração do genoma. Ao sofrer o efeito dos agentes cancerígenos classificados como oncopromotores, as células geneticamente alteradas originam focos de proliferação celular (FARBER \& SARMA, 1987), transformando-se em malignas, de forma lenta e gradual. Essa transformação requer um longo e contínuo contato com o agente cancerígeno promotor. A suspensão do contato muitas vezes interrompe o processo nesse estágio, caracterizado pela reversibilidade (PITOT, 1989).

O terceiro e último estágio, o da "progressão", se caracteriza pela instabilidade progressiva do cariótipo e multiplicação descontrolada autonômica e irreversível das células alteradas (PITOT, 1993). Nesse estágio, os focos de proliferação resultam em neoplasias malignas com capacidade invasiva e metastática, evoluindo até o surgimento 
das primeiras manifestações clínicas da doença (FARBER \& SARMA, 1987; FARBER \& RUBIN, 1991; DRAGAN et al., 1995; PITOT et al., 1996; BRASIL. MINISTÉRIO DA SAÚDE, 2000).

O processo de carcinogênese depende da proliferação, diferenciação e morte das células. A proliferação celular desempenha um papel importante no processo de formação do tumor (TOMATIS, 1993; FARBER, 1995) por aumentar a freqüência de mutações através da indução de erros na replicação do DNA, reduzir o tempo de reparo do DNA e estar envolvida na determinação da relação dose-resposta para alguns carcinogênicos (TOMATIS, 1993).

Seu aumento pode ser desencadeado por agentes exógenos, como os carcinógenos químicos genotóxicos ou promotores da carcinogênese, ou endógenos, incluindo os radicais livres de oxigênio produzidos pela respiração e fagocitose, danos celulares, despurinização e alterações no sistema de reparo do DNA. (LOEB, 1989; AMES \& GOLD, 1990; AMES et al., 1995).

Existem outras evidências que relacionam o início de um tumor colorretal com o desequilíbrio no metabolismo do ácido araquidônico. Uma super-expressão patológica da enzima COX-2 resulta em produção excessiva de prostaglandinas e tem sido encontrada nos estágios iniciais da carcinogênese. Essa super-expressão ocorre para sinalizar as vias inflamatórias e de reparo tecidual, tornando-se ativada no curso da promoção de um tumor, e, devido a mecanismos autócrinos e auto-estimulatórios, leva à autopromoção do tumor (MARKS \& FURSTENBERGER, 2000). 


\subsection{Alimentação, nutrição e câncer}

Além dos fatores predisponentes, como hereditariedade, adenomas e doença inflamatória, acredita-se que fatores ambientais, em especial a dieta, estejam implicados nas diferenças de incidências populacionais. Os fatores dietéticos que têm recebido maior atenção são: 1- ingestão energética excessiva em relação às necessidades; 2baixo conteúdo de fibras vegetais não absorvíveis; 3-alto conteúdo de carboidratos refinados; 4- consumo elevado de carnes vermelhas; 5-diminuição de fatores protetores da mucosa (vitaminas) contidos na dieta (FRANKS, 1990).

Entre os fatores dietéticos sugeridos como de risco para o câncer, talvez nenhum tenha atraído tanta atenção quanto a ingestão de gordura (KUSHI et al., 2002).

A revisão efetuada pelos epidemiologistas ingleses Doll e Peto, publicada em 1981, sugeriu que seria plausível reduzir em 35\% (com uma variação de 10 a 70\%) a mortalidade por câncer nos EUA por meio de modificações realizadas na alimentação. Como fatores protetores, esses autores ressaltam o papel de vitaminas antioxidantes, de vegetais ricos nesses compostos e de microconstituintes dos alimentos, como fibras e alimentos que tornam as fezes volumosas. Além disso, aspectos da alimentação mencionados como possíveis causas de câncer foram os consumos de alimentos em excesso, as gorduras (cânceres de mama, cólon e reto) e carnes (cânceres de cólon e reto).

Dez anos mais tarde, Doll (1992) reafirmou suas conclusões, continuando a atestar que "a estimativa de que o risco de câncer fatal pode ser reduzido em $35 \%$ por meio de modificações na alimentação continua a ser razoável”. 
Wynder e Gori (1977) propõem que o "potencial de se prevenir todos os cânceres seria efetivamente de $80-90 \%$ ". Sugerem, ainda, que o fator alimentação responderia por $40 \%$ de todos os casos de cânceres em homens e $60 \%$ em mulheres. As causas alimentares do câncer incluiriam, em geral, uma hiperalimentação, bem como gorduras e carnes em excesso.

Em 2003, na American Cancer Society para a prevenção do CCR, destcou vários itens passíveis de serem convenientemente modificados, dentre os quais se inclui a alimentação, que deve ser "saudável". Isso pode ter implicação ampla e complexa, dado o grande número de alimentos, mesmo entre os vegetais, que têm sido estudados e relacionados com o CCR, muitas vezes com controvérsias. A despeito disso pode-se seguramente afirmar que alimentação gordurosa e a pobre em fibras podem facilitar o aparecimento do CCR.

Alguns estudos demonstraram que em humanos uma dieta rica em gordura e carne e pobre em fibras aumentam significativamente a formação de radicais hidroxil nas fezes, os quais contribuem para o aumento do risco de CCR (ERHARDT et al.,1997).

Em relação à gordura de origem animal, a suspeita está alicerçada na verificação de que a freqüência de aparecimento do CCR é maior entre os povos em que $40 \%$ ou mais das calorias totais ingeridas são provenientes de gordura, contrário ao que ocorre entre aqueles em que a gordura responde por não mais do que $10 \%$ do total das calorias ingeridas (ROSE et al., 1986; REDDY, 1981).

Estudos experimentais apresentaram resultados similares. Em estudo recente, ratos expostos a carcinógeno químico e dieta gordurosa mostraram um aumento significativo dos FCAs, duas vezes maior que o de animais com uma dieta normal (GETER et al., 2004). 
Em ratos, a dieta rica em gordura aumenta o número de FCAs (lesões précancerosas no cólon) induzido pelo azoximetano (MOROTOMl et al., 1997).

A probabilidade de carcinogênese do cólon pode ser aumentada em decorrência da ação mutagênica de radicais livres, oriundos de reações oxidativas (KNIGHT, 1995). Essas espécies reativas do metabolismo do oxigênio podem potencializar a proliferação epitelial colônica. Esse aumento poderia predispor a um processo de malignização da mucosa (BERTRAM et al., 1987).

\subsection{O Orlistat}

O Orlistat exerce sua atividade terapêutica no lúmen do trato gastrintestinal, inibindo a enzima lipase pancreática, responsável pela hidrólise das triacilglicerídeos normalmente ingeridos na dieta. Esse medicamento é um derivado da lipstatina, que por sua vez é um inibidor natural da lípase produzida pelo Streptomyces toxytricini (GUERCIOLINI, 1997).

O Orlistat não tem efeito inibitório significativo sobre outras enzimas digestivas, tais como amilase, tripsina, quimiotripsina e fosfolipase (RAO et al., 2001). As gorduras ingeridas geralmente têm cadeias moleculares longas, que não podem ser absorvidas pela mucosa do intestino. A lipase quebra essas moléculas de triacilglicerídeos em tamanho menores. Essa droga, ao inibir a enzima, provoca uma queda de absorção de cerca de $30 \%$ das gorduras de cadeias longas, eliminadas nas fezes, causando esteatorréia (RAO et al., 2001; HANIF \& KUMAR, 2002). 
Em doses terapêuticas, o Orlistat não inibe a lipase sistêmica. A droga e seus metabólitos são eliminados por excreção renal e biliar, sendo que a via renal é menor que $2 \%$ e a excreção completa (fecal e urinária) se dá dentro de 3 a 5 dias (ZHI et al., 1996).

Quando adicionado à dieta de ratas, o medicamento reduziu a atratividade da dieta. Portanto, ele pode ser efetivo na redução da absorção da gordura ingerida, tanto pela inibição da lipase pancreática quanto pela redução do consumo (ACKROFF \& SCLAFANI, 1996).

É sabido que a droga exerce ação tópica no estômago e intestino delgado, com absorção sistêmica reduzida, sendo considerada uma droga segura e efetiva no tratamento da obesidade. Apesar disso, alguns efeitos adversos já foram descritos dentre eles necrose hepato celular, constipação, poliúria e polidipsia (LAU \& CHAN, 2002., PACKARD et al, 2002).

Provavelmente inibindo a lipase pancreática o aumento do teor de gordura na mucosa colônica poderá potencializar o processo de malignização da mucosa.

\subsection{Modelo experimental de carcinogênese química pela Dimetilhidrazina}

Os modelos experimentais disponíveis para a indução de câncer de cólon em animais de laboratório utilizam agentes químicos. Tais modelos têm sido de grande importância em estudos sobre diversos aspectos da morfologia e patogênese da doença, contribuindo para o aperfeiçoamento do seu diagnóstico, prevenção e tratamento. 
A administração de $\mathrm{DMH}$ em ratos constitui modelo experimental amplamente utilizado na pesquisa da CCR, pois os animais raramente desenvolvem CCR espontaneamente. Os cancerígenos induzem a formação de lesões colorretais em quase todos os animais, com a vantagem de apresentar pouca toxicidade aguda (OLIVEIRA et al, 2001).

Essa forma de câncer pode ser induzida em modelos experimentais, utilizando cancerígenos químicos como o $\mathrm{DMH}$, que possui um alto grau de especificidade para o cólon de variadas espécies de roedores, acarretando aumento na proliferação celular do cólon, com: a) aumento do número total de células por cripta; b) aumento do número de células marcadas por timidina; c) aumento do índice mitótico (razão entre o número de células marcadas e o número total de células) nas criptas (DESCHNER, 1974; REDDY et al., 1975; LAMONT \& O'GORMAN, 1978; ROGERS \& NAUSS, 1985; OLIVEIRA et al, 2001).

Dessa forma, acredita-se que pólipos adenomatosos e carcinomas são processos patológicos progressivos, que acontecem como conseqüência da administração de DMH e provocam as modificações na proliferação celular. Nessas situações, as alterações morfo-cinéticas epiteliais, em resposta a $\mathrm{DMH}$, poderiam ser consideradas marcadores precoces da transformação neoplásica (OKADA et al., 1996).

Os ensaios que verificam a resposta proliferativa epitelial precoce em resposta à aplicação de DMH têm se configurado como adequados para se testar o potencial de aumentar ou diminuir o risco de câncer em diversas situações experimentais. Assim, por exemplo, verifica-se que fatores dietéticos que diminuem o risco para o desenvolvimento de CC também reduzem a resposta hiperproliferativa da mucosa à ação de 
carcinógenos químicos, o que mostra que esses fatores atuam na etapa precoce da transformação neoplásica (SINGH et al., 1997).

\subsection{Biomarcadores da carcinogênese colônica}

\subsubsection{Focos de criptas aberrantes}

Os Focos de Criptas Aberrantes (FCAs) foram primeiramente descritos por Bird, em 1987, sendo considerados precursores de lesões que desenvolvem CCR.

Embora ainda permaneçam desconhecidos muitos dos eventos que ocorrem entre o aumento da população celular das criptas e o aparecimento do câncer é bem estabelecido que em indivíduos humanos com alto risco para câncer a proliferação celular da mucosa colônica está aumentada e, freqüentemente, se manifesta através de projeção do compartimento proliferativo das criptas em direção à luz do tubo gastrintestinal (OLIVEIRA et al., 2001).

Essas lesões se caracterizam morfologicamente por apresentarem criptas com aberturas terminais alteradas, espessamento epitelial com células proeminentes e tamanho maior que as criptas adjacentes (SIU et al., 1997).

Os FCAs foram extensivamente usados para detecção de fatores que influenciam a carcinogênese colorretal em ratos tratados com carcinógenos químicos, como a 1,2Dimetilhidrazina (MCLELLAN, 1991; THORUP, 1994).

Estudos evidenciaram a presença de grande número de FCAs em ratos tratados com cancerígenos químicos, como $\mathrm{DMH}$, sendo que números significativos dos ratos 
desenvolveram tumores colônicos, mostrando que os FCAs são bons marcadores de lesões pré neoplásicas em cólons (PARK et al., 1997). Tais lesões podem ser induzidas pela administração da $\mathrm{DMH}$ em animais de laboratório, de forma dose-dependente (DESCHNER, 1974). São facilmente visíveis em exames microscópicos do cólon, corado com azul de metileno (BIRD, 1995).

Após a constatação dos FCAs, foram realizados muitos estudos para estimar o seu número, tamanho e distribuição no cólon de roedores submetidos a ação de cancerígenos. Sendo assim, constatou-se em ensaios que a quantificação e classificação dos FCAs são excelente parâmetro, com boa especificidade e sensibilidade, para se avaliar o potencial de proteção ou de risco para o câncer em modelos experimentais (PARK et al., 1997; BIRD, 1987; BIRD, 1995).

Os FCAs são considerados bons marcadores biológicos do processo de transformação neoplásica, por serem as modificações mais iniciais do desenvolvimento neoplásico em nível morfológico (BIRD, et al., 1987).

Não se conhecem os mecanismos da transformação de FCAs em neoplasias, mas sabe-se da existência de relação entre alterações de oncogenes e de mecanismos genéticos com a formação de FCAs. Assim, por exemplo, mutações no gene K-ras (oncogene) e no gene p53 (gene supressor - regulador do ciclo celular e apoptose em resposta à lesão do DNA) estão envolvidas no desenvolvimento de câncer de cólon, associadas ao aumento do número de FCAs por campo e desenvolvimento de tumores colônicos (SHIVAPURKAR et al., 1997). Um outro estudo mostra que FCAs com multiplicidade e aumento de criptas apresentam resistência à morte celular por apoptose, induzida pela $\mathrm{DMH}$, da mesma forma que corre em lesões pré-neoplásicas de câncer de fígado (BIRD, 1995). 
Com isso, Shivapurkar et al. (1997) presumiu dois eventos genéticos importantes implicados na carcinogênese do cólon: mutações do gene K-ras e no gene p53. As mutações em K-ras são detectadas mais precocemente do que em p53 que são detectadas em fases mais avançadas da carcinogênese do cólon. Seu objetivo maior, neste estudo, foi comparar a natureza das alterações genéticas em K-ras e p53 entre os FCAs, em pacientes com câncer de cólon. Foram escolhidas criptas da mucosa normal de pacientes com câncer e comparadas com tecido canceroso. Os resultados demonstraram uma correlação entre alelos do K-ras e os FCAs correspondendo a pacientes com CC. Na análise do gene p53, ficou demonstrada a presença de mutações em FCAs. Os resultados sugerem um subsistema de FCAs com multiplicidade mais alta progredindo para lesões mais avançadas, as quais deveriam ser exploradas como marcadores de risco de câncer de cólon.

Quando as criptas aberrantes isoladas ou em focos são encontradas na mucosa de ratos tratados com carcinógenos, também mostram alterações relacionadas ao processo de transformação neoplásica, podendo ser utilizadas como biomarcadores, indicadores da provável progressão para o câncer. Constatou-se a existência de linhagens mais resistentes e mais suscetíveis ao aparecimento de FCAs e posterior desenvolvimento de câncer de cólon quando induzidos por cancerígenos como a DMH (ROSEMBERG \& LIU, 1995; MCLELLAN et al, 1991).

Graças a esses estudos, hoje é possível se avaliar o papel de diversos fatores (nutrientes ingeridos na dieta, drogas, inflamação crônica e ulcerações da mucosa) na predisposição ou proteção ao desenvolvimento do câncer de cólon nas várias fases da carcinogênese colorretal. 


\subsubsection{A proliferação celular epitelial durante as etapas da carcinogênese}

O epitélio do trato gastrintestinal tem como mecanismo primordial de crescimento a proliferação celular. Uma alta atividade proliferativa na região basal das criptas da mucosa intestinal é estritamente controlada por numerosas proteínas regulatórias, com características semelhantes às das oncoproteínas, genes supressores de tumor e ciclinas, incluindo o Antígeno Nuclear de Proliferação Celular (PCNA) (MURAKAMI et al., 1995; QUINN et al., 1990; YU et al., 1992).

Esse processo é acompanhado por acúmulo de mutações e mudanças na expressão dos oncogenes e genes supressores tumorais, conduzindo a transformação de células afetadas e modificações dentro de uma célula maligna (FEARON \& VOGELSTEIN, 1990; SHIPTZ et al, 1997). Um outro mecanismo que contribui na transformação para malignidade é o aumento das células em proliferação (HALL et al., 1995).

O PCNA é uma proteína nuclear associada ao ciclo celular (HALL et al.,1990) que detecta o antígeno nuclear de células em proliferação nas fases "G1"e "S" quando elas ficam fortemente marcadas.

Para que ocorra a divisão celular, um processo complexo é iniciado. Várias proteínas são ativadas, podendo-se destacar fatores de crescimento e seus receptores, bem como proteínas que estimulam a proliferação e o desenvolvimento da célula normal. Assim, a divisão celular é positivamente regulada ou estimulada, por meio de vias sinalizadoras (VERMEULEN et al., 2003). 
Genes estimuladores da proliferação celular incluem os proto-oncogenes, enquanto os inibidores são os supressores de tumor. Esses últimos modulam a progressão do ciclo celular, mantendo a célula em latência ou induzindo a sua morte, caso as condições do ciclo celular não estejam apropriadas (YONISH - ROUACH, et al., 1991). Mutações ou modificações na expressão desses genes conferem à célula vantagens de crescimento e desenvolvimento em relação ás células normais (VERMEULEN et al., 2003). Os genes supressores de tumor, ou anti-oncogenes, estão envolvidos com a inibição da expressão do fenótipo maligno, podendo ser inativados por mutações durante o processo da carcinogênese (VENIT, 1994). Uma mutação que venha a inibir esses genes poderá resultar em perda de mecanismos naturais de controle da proliferação, resultando em multiplicação excessiva das células. Os protooncogenes estão relacionados com a divisão e diferenciação celular normal. Uma vez mutados, são ativados em oncogenes e podem atuar em vias intracelulares, envolvidas com o controle da proliferação celular, sem a necessidade de estímulos externos. Exemplos de proto-oncogenes são o c-myc e K-ras (NEMETH et al., 2003).

Inúmeros trabalhos relatam a aplicação de anticorpos monoclonais, dirigidos contra o antígeno nuclear de células proliferativas (PCNA), por ser este marcador um útil indicador do comportamento biológico de alguns tumores.

A ausência de PCNA nas reações de duplicação de DNA resulta no acúmulo de fitas seqüenciais nascentes e até mesmo na quiescência das células. $O$ gene que codifica o PCNA tem sido clonado em diversas espécies e, embora ocorram pequenas diferenças no DNA, existe considerável semelhança entre o PCNA humano e de outras espécies (MCMORMICK \& HALL, 1992). 
A concentração do PCNA é variável durante as etapas do ciclo celular, sendo maior na fase $\mathrm{G} 1$ tardia, com pico na fase $\mathrm{G} 1 / \mathrm{S}$, estando praticamente ausente nas fases G2 e M (HALL et al.,1990; KURKI et al., 1986; TSUJl et al., 1995). De acordo com McMormick \& Hall (1992), o PCNA pode não ser específico da fase $S$ ou, necessariamente, estar relacionado com o ciclo celular, podendo estar associado ao reparo do DNA ou ser expresso por influência de fatores de crescimento em células que não estejam no ciclo celular. Tsuji et al. (1995) relatam a correlação entre os índices de PCNA e p53 como indicadores do potencial maligno de neoplasias na mucosa oral, sendo a ocorrência da expressão dos mesmos um fator importante num prognóstico desfavorável. 
Ainda não se conhecem os efeitos do acúmulo de gordura na mucosa do cólon em conseqüência da ação do Orlistat. Tendo em vista que o excesso de gordura na luz intestinal, proveniente de dieta hipergordurosa, já foi correlacionado a maior risco de câncer de cólon, a hipótese deste estudo é verificar se o uso de Orlistat, por também acentuar o teor de gordura intra-luminal do cólon, poderia influenciar a carcinogênese colônica. 
3. OBJETIVOS 
1. Verificar os efeitos do Orlistat na formação de Focos de Criptas Aberrantes e na resposta hiper-proliferativa celular epitelial da mucosa, decorrentes da ação da Dimetilhidrazina.

2. Verificar se existe similaridade entre os eventuais efeitos do Orlistat e da dieta hipergordurosa nos parâmetros acima mencionados 


\section{MATERIAL E MÉTODOS}




\subsection{Animais}

Foram utilizados ratos Wistar machos, de aproximadamente 160-180g, no início do experimento. Os animais foram provenientes do Biotério Central da Faculdade de Medicina de Ribeirão Preto da Universidade de São Paulo (FMRP-USP), mantidos no Biotério do Departamento de Patologia em condições de temperatura ambiente constante de $25^{\circ}$ e ciclo noite-dia de doze horas. Foram alimentados com dieta padrão Purina ${ }^{\circledR}$, comercialmente disponível para ratos, e água de torneira ad libitum. Os animais foram acomodados (4 animais por gaiola) em gaiolas padrão, de polietileno, com tampas metálicas e assoalho forrado com maravalha, mantidos segundo as normas da Comissão de Ética em Experimentação Animal da FMRP-USP.

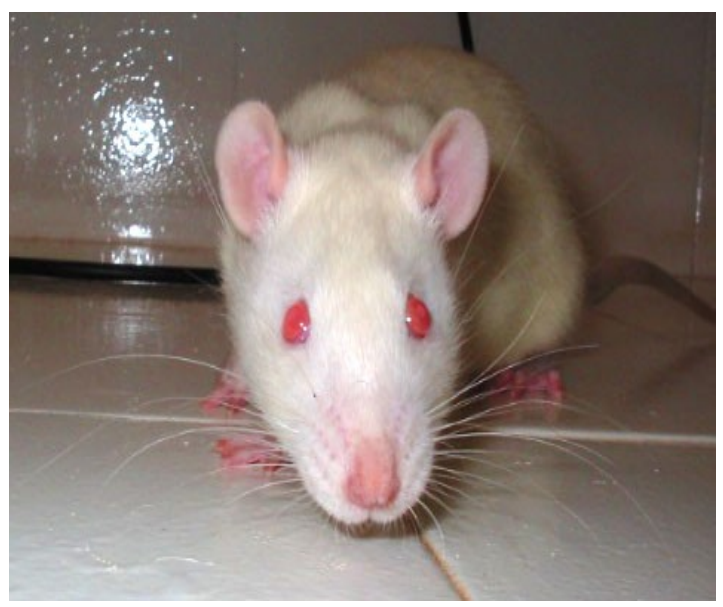

Figura 1- Rato wistar

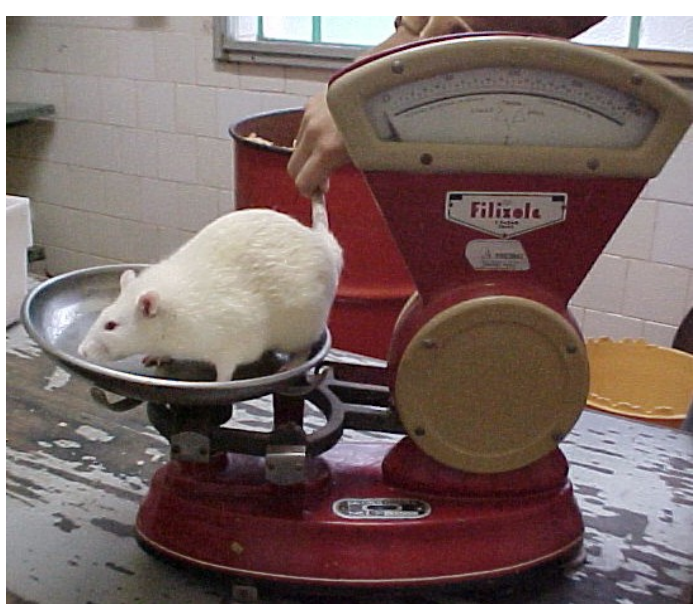

Figura 2- Pesagem do animal 


\subsection{Preparação da ração}

A ração foi preparada no Departamento e Patologia da Faculdade de Medicina. A ração utilizada pelo Biotério USP da marca NUTRILABOR GUABI foi borrifada óleo de algodão (para aumentar o teor de gordura) e/ou Orlistat na concentração de 1 mg de OL para $1 \mathrm{~g}$ de óleo. A droga foi dissolvida em clorofórmio, e após o borrifamento a ração foi colocada na estufa (24 horas) para evaporá-lo.

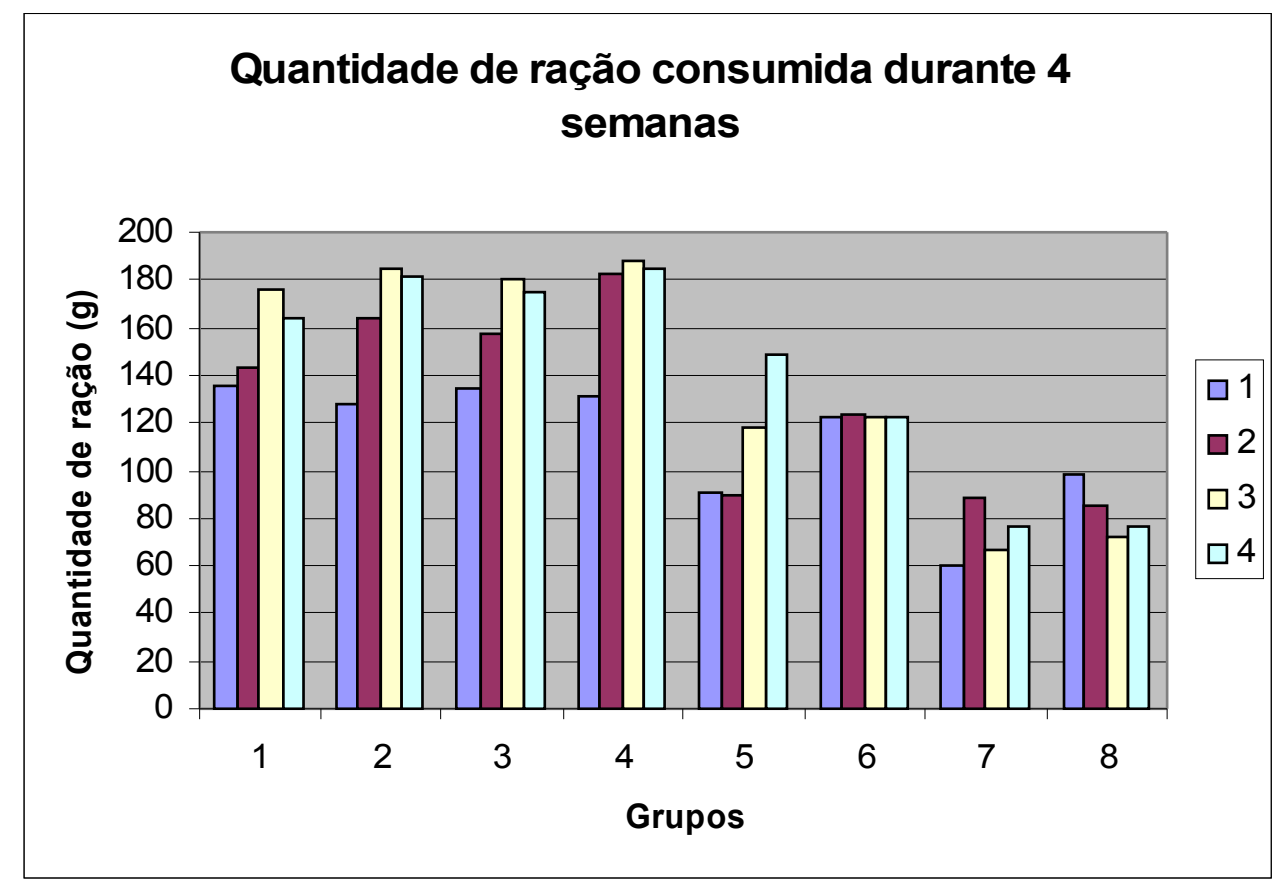

Gráfico 1 - Quantidade de ração (g) consumida durante 4 semanas

Primeira semana

Segunda semana

Terceira semana

Quarta semana 


\subsection{Delineamento experimental}

Após o período de adaptação de uma semana, os animais foram divididos aleatoriamente em oito grupos (8 ratos por o grupo). Os grupos 1, 2, 3 e 4 receberam Purina alimento padrão para rato. Os grupos de 5 a 8 foram alimentados com uma dieta padrão enriquecida com óleo de algodão. Os grupos 3, 4, 7 e 8 receberam duas doses do carcinógeno Dimetilhidrazina $(25 \mathrm{mg} / \mathrm{Kg})$ cada. Os grupos 2, 4, 6 e 8 foram alimentados com uma dieta suplementada com o Orlistat (200 mg/kg), como descrito na literaturas (HAFKAMP et al., 2005).

O delineamento experimental é resumido como se segue:

\begin{tabular}{|c|c|c|c|}
\hline Grupos & Dieta hipergordurosa & Orlistat & $\mathrm{DMH}$ \\
\hline 1 & - & - & - \\
\hline 2 & - & + & - \\
\hline 3 & - & - & + \\
\hline 4 & - & + & + \\
\hline 5 & + & - & - \\
\hline 6 & + & + & - \\
\hline 7 & + & - & + \\
\hline 8 & + & + & + \\
\hline
\end{tabular}

O peso corporal foi avaliado durante o período experimental. Todos os ratos foram mortos após 30 dias da segunda dose de $\mathrm{DMH}$. Na autópsia, o intestino grosso foi aberto longitudinalmente próximo à borda mesentérica, em toda sua extensão, fornecendo cortes transversais para a identificação das criptas colônica e quantificação do FCAs como descrito anteriormente (PIVA-DEMARZO MM \& GARCIA SB, 2004). O 
cólon distal e o reto foram fixados em formalina e amostras foram coletadas para exame histológico.

Outros segmentos cortados como anéis do órgão foram embebidos em parafina e o bloco foi cortado, mantendo a orientação transversal original em série, para fornecer seções anelares, usadas para imunoistoquímica.

\subsection{Imunoistoquímica e morfometria}

Para estimar a proliferação celular epitelial da mucosa colônica em todos os animais, efetuou se cortes finos $(4 \mu \mathrm{m})$ de cólon, embebidos em parafina e imunomarcados com o antígeno de proliferação nuclear celular (PCNA), usando a (PCNA/Novocastra). Em cada cólon, os núcleos celulares foram contados em 100 criptas colônicas. O índice de PCNA (iPCNA) foi estimado como uma relação de núcleos positivamente marcados em relação ao total de núcleos contados em 100 criptas. A análise estatística foi executada usando o teste de ANOVA. Uma probabilidade de $0,05(p<0.05)$ foi considerada estatisticamente significativa.

\subsection{Indução de lesões pré-neoplásicas em mucosa colônica}

No início do tratamento, os animais dos grupos 3, 4, 7, e 8 receberam aplicação intraperitoneal da primeira dose do cancerígeno $\mathrm{DMH}$ e, após 15 dias, a segunda e última dose, de $25 \mathrm{mg} / \mathrm{kg}$. Esses grupos foram estabelecidos para análise comparativa 
da incidência de adenocarcinoma no epitélio colônico, induzida pela DMH nos cólons normais.

\subsection{Preparo do Carcinógeno}

Foi utilizada Symetrical Dimethylhydrazina Dihydrochloride (Sigma Co), dissolvida na concentração de $800 \mathrm{mg} / 100 \mathrm{ml}$ de solução de água destilada, contendo $37 \mathrm{mg} / 100 \mathrm{ml}$ de EDTA como agente estabilizador. A solução foi mantida em pH 6,5 pela adição de 15 a 20 gotas de hidróxido de sódio 0,1 normal $(\mathrm{N})$. A solução de $\mathrm{DMH}$ foi preparada imediatamente antes de cada aplicação.

\subsection{Segurança para a DMH}

A DMH foi armazenada na geladeira do próprio laboratório, em frascos devidamente identificados.

A manipulação foi feita em pequenas quantidades, com os pesquisadores utilizando aventais, máscaras, luvas e gorros. Após manipulação da droga o material utilizado foi imerso em solução saturada de permanganato de potássio, para neutralização.

\subsection{Aplicação do Carcinógeno}


Os grupos 3, 4, 7 e 8 receberam injeção em duas doses intra-peritoniais de $\mathrm{DMH}$ (25 mg/Kg de peso corporal).

\subsection{Sacrifício dos animais}

Os animais foram sacrificados no $30^{\circ}$ dia de tratamento, utilizando a câmara de $\mathrm{CO}_{2} \mathrm{e}$, em seguida, os ratos foram submetidos a tóraco-laparotomia mediana para inventário das cavidades torácicas e ressecção dos cólons para estudo.

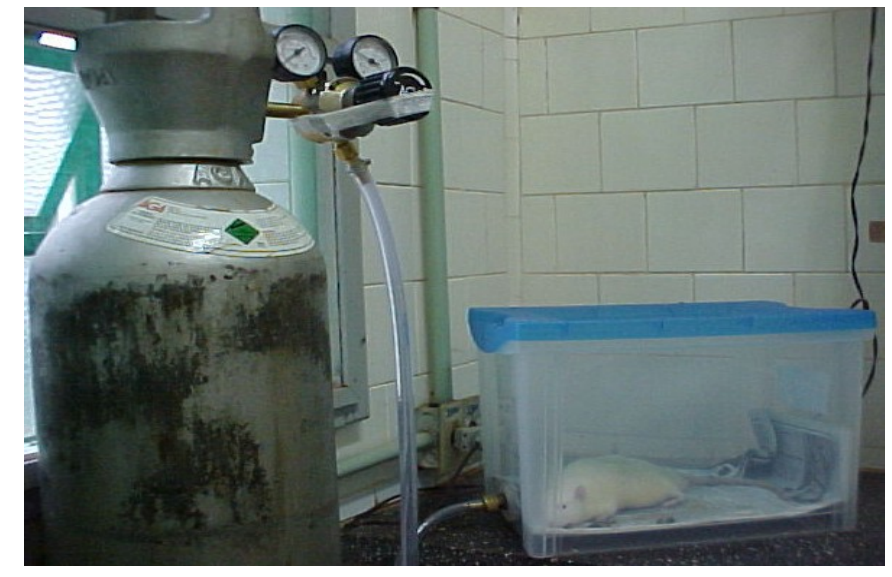

Figura 3- Rato em câmara de $\mathrm{CO}_{2}$ 


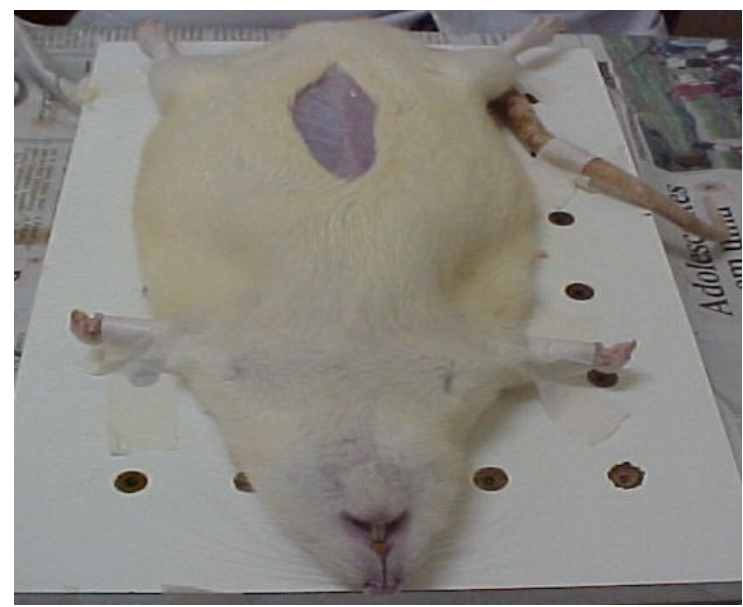

Figura 4- Incisão na pele

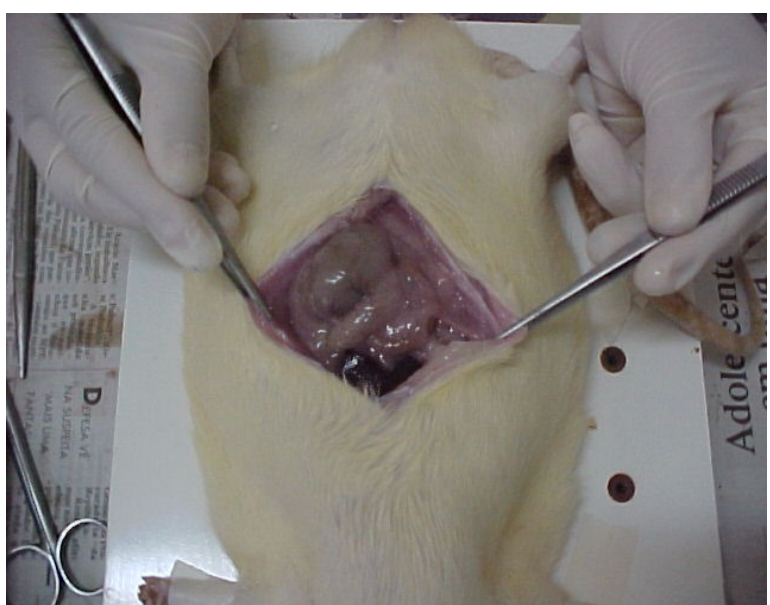

Figura 5- Laparatomia mediana

\subsection{Coleta e processamento do cólon}

Foi ressecado, de cada animal, todo seguimento distal do cólon. Esse seguimento foi lavado em solução salina tamponada. A peça foi então aberta longitudinalmente pela borda mesentérica e, em seguida, estendida em molduras de papelão, identificadas adequadamente. Todo o material foi mergulhado em recipiente cilíndrico de vidro, com solução de formaldeído a 10\% e armazenado em temperatura ambiente até o seu processamento.

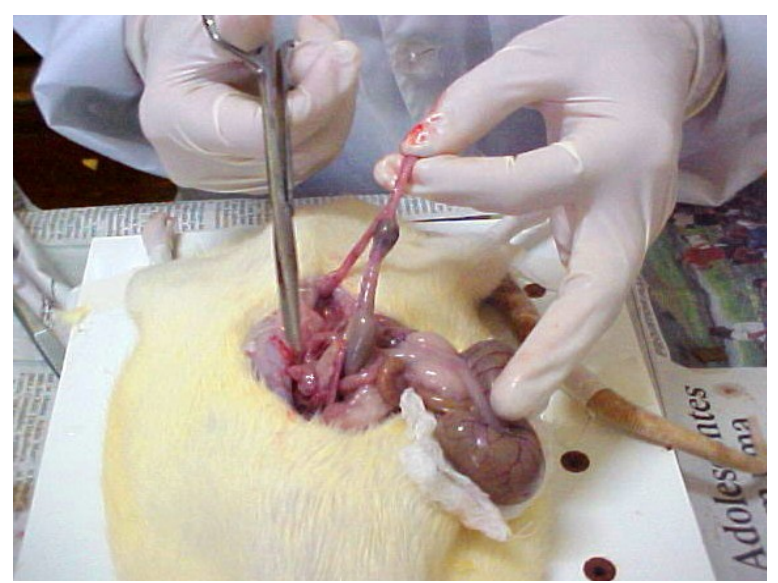

Figura 6- Isolamento do cólon

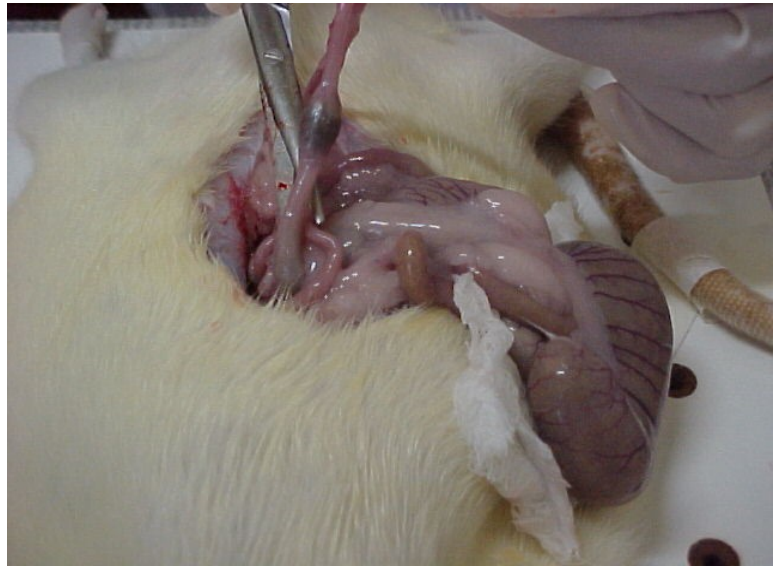

Figura 7- Isolamento da porção mais distal do cólon 


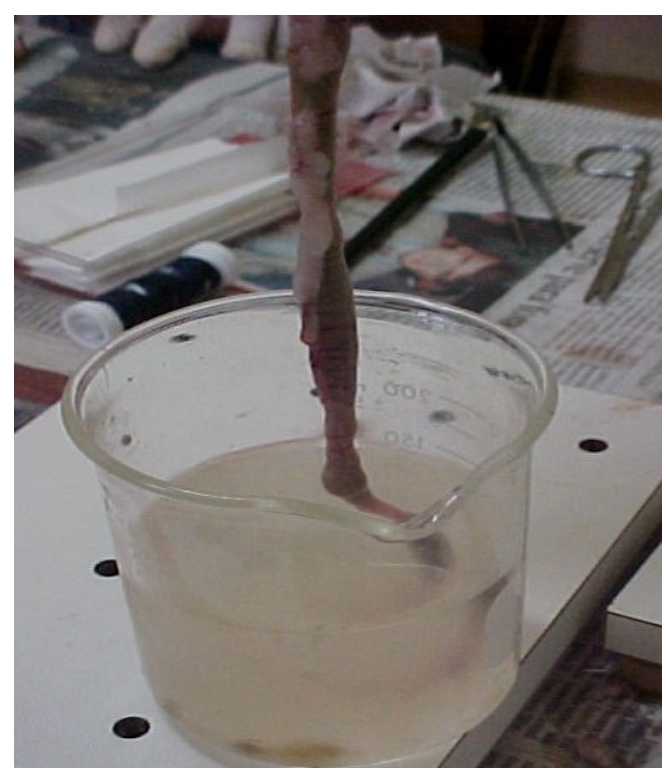

Figura 8- Lavagem de cólon

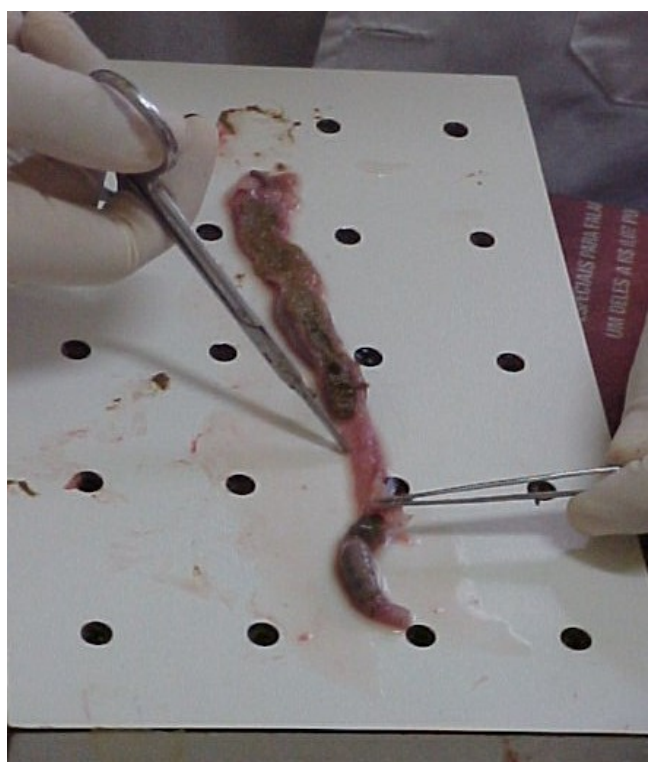

Figura 9- Peça do cólon

\subsection{Análise histológica}

Para a confecção das lâminas, as amostras analisadas foram submetidas ao procedimento padrão, ou seja, desidratadas, diafanizadas, impregnadas em parafina e cortadas com micrótomo de forma a obter-se cortes de $5 \mu \mathrm{m}$ de espessura.

Os cortes foram obtidos de cada fragmento e corados por métodos diferentes: Técnica de rotina H\&E e PCNA (Proliferation cell nuclear antigen)

\subsection{Proliferação celular epitelial}

Na contagem das células em proliferação foi observado um aumento significativo do número de células positivamente marcadas com PCNA (imunomarcação do antígeno para avaliação da proliferação celular), com intuito de estimar o epitélio da mucosa. 
Foi realizada a contagem do número de células positivas ao PCNA por campo, utilizando microscópio de luz direta, com ocular 10x e objetiva 40x. Inicialmente foram contadas todas as células do campo e, posteriormente, somente as células fortemente marcadas pela PCNA, cuja freqüência foi expressa em termos percentuais em relação ao total.

Obteve-se cortes de 4 a $5 \mu \mathrm{m}$ de espessura, incluídos em parafina nas lâminas e utilizado o complexo estreptavidina-biotina-peroxidase (HSU, 1981), adaptado às condições laboratoriais utilizadas neste estudo. As lâminas foram incubadas com anticorpo monoclonal específico anti-PCNA, diluído em tampão PBS durante 16 a 18 horas, a $4^{\circ} \mathrm{C}$.

Em seguida, foram lavadas em tampão PBS com três trocas, de três a cinco minutos cada, e incubadas com anticorpo secundário biotinilado (anti-lg) diluído em PBS, durante 30 minutos, a $37^{\circ} \mathrm{C}$. Observaram-se as lâminas controles, verificando-se o desenvolvimento de precipitado castanho-dourado, como produto final da reação. Finalmente, as lâminas foram coradas com hematoxilina de Harris.

O índice de expressão do PCNA foi quantificado pela observação do núcleo celular, marcado com anticorpo monoclonal anti-PCNA. Esse processo foi conduzido em microscópio óptico comum, munido de lente ocular de 10x e objetiva de 40x, com magnificação final de 400x.

A reação de expressão celular do PCNA foi considerada positiva quando a marcação nuclear ocorreu de modo difuso ou granular, com pontos de intensidade variável ou com distribuição homogênea, independente da sua intensidade (DUKES, 1932). 


\subsection{Avaliação dos Focos de Criptas Aberrantes}

Foi feito um screening da mucosa de todo o cólon, através de exames com lupa. Os FCAs foram identificados, quantificados e calculada a freqüência (por unidade de área, em $\mathrm{cm}^{2}$ ) e distribuição ao longo do cólon, segundo protocolo estabelecido por BIRD (1995).

\subsection{ANÁLISE ESTATÍSTICA}

Os resultados das médias das contagens do número de $\mathrm{FCAs} / \mathrm{cm}^{2}$ e dos índices de células positivamente marcadas pelo PCNA (iPCNA) por cripta foram comparados entre os oito grupos, através do Teste ANOVA. As diferenças foram consideradas estatisticamente significativas quando $p<0,05$. 
5. RESULTADOS 
Todos os animais sobreviveram ao período experimental e não mostraram nenhum sinal clínico da deficiência nutritiva. No fim da experiência, o peso corporal médio dos animais não foi estatisticamente diferente entre os grupos experimentais.

Os estudos histopatológicos mostraram que FCAs foram observados somente nos cólons de animais que receberam DMH. Na sua maioria, foram observados FCAs constituídos de apenas uma cripta aberrante, que se apresentava com espessamento epitelial e deformidades diversas da estrutura, conforme ilustra a Figura 10.

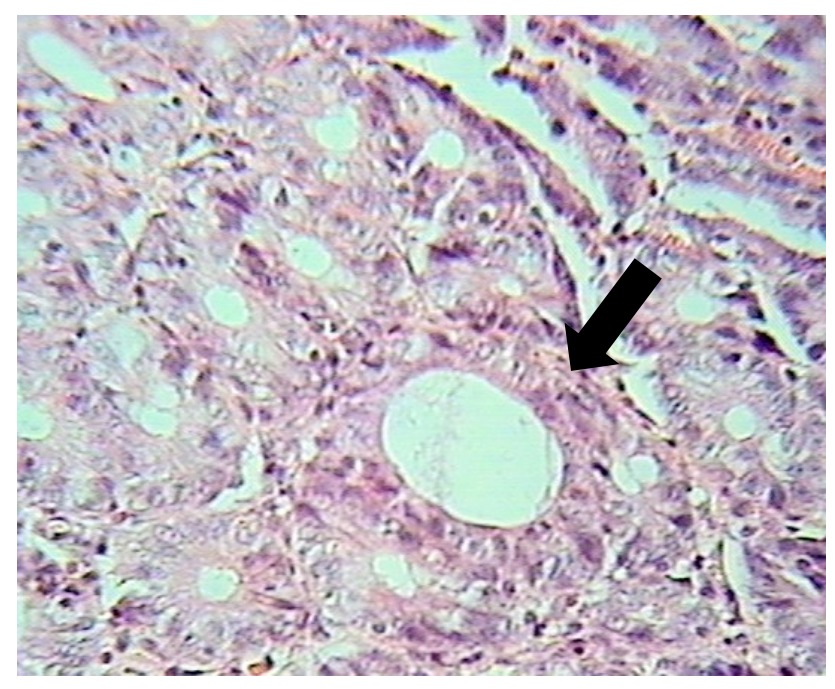

Figura 10. Cripta aberrante circundada por criptas de aspecto normal

Como mostrado no gráfico 2, os grupos 4 e 7 apresentaram um número similar dos FCAs, maiores do que no grupo 3. O grupo 8 apresentou um aumento adicional no número de FCAs quando comparado aos grupos 4 e 7 . 


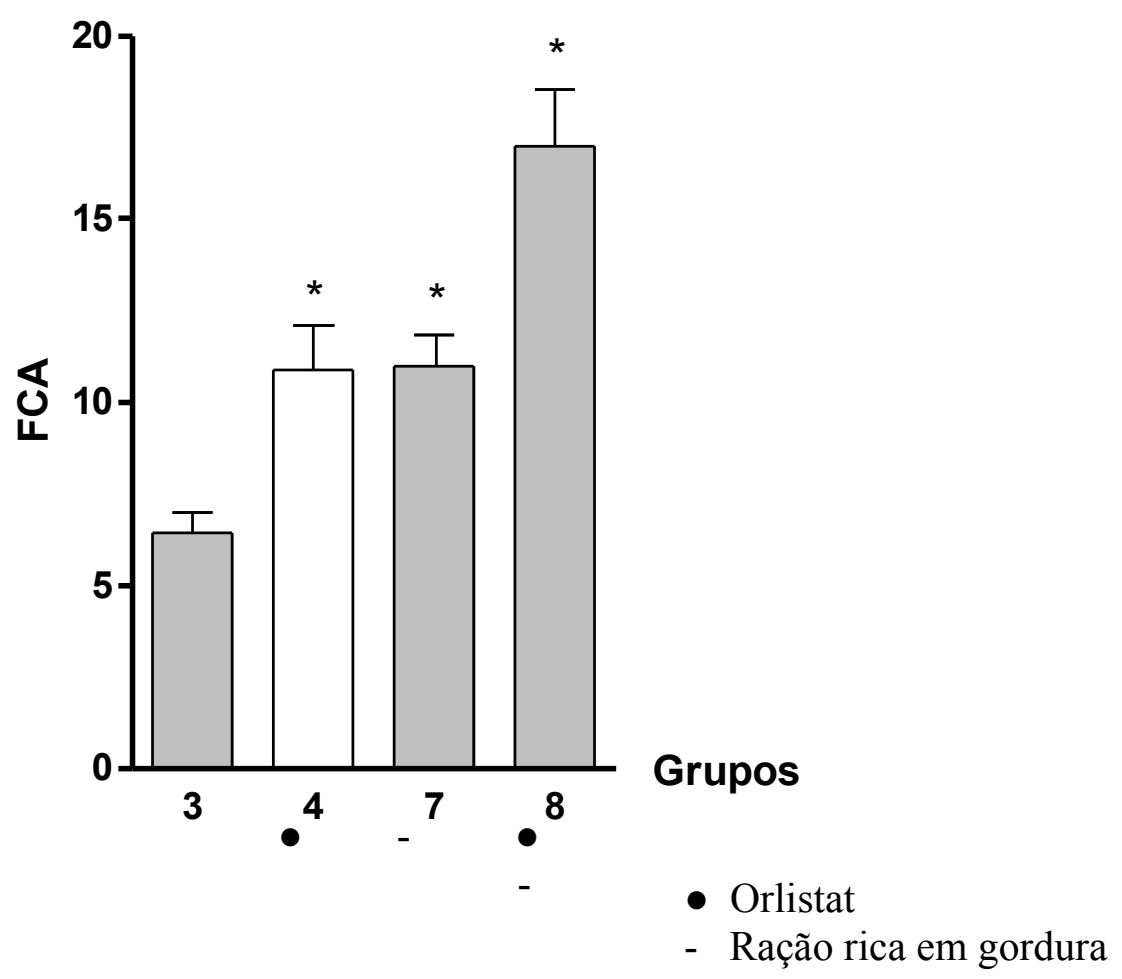

Gráfico 2 - Número de Focos de Criptas Aberrantes por $\mathrm{cm}^{2}$ de mucosa de cólon, em animais tratados com Dimetilhidrazina.

Grupo 3 controle;

Grupo 4 recebeu ração padrão e Orlistat;

Grupo 7 recebeu dieta rica em gordura

Grupo 8 recebeu dieta rica em gordura e Orlistat.

- $8>7=4>3(p \leq 0,05)$ 
A imuno-marcação do PCNA mostrou a presença de núcleos celulares fortemente marcados nas amostras de todos os grupos experimentais, conforme ilustra a Figura 11.

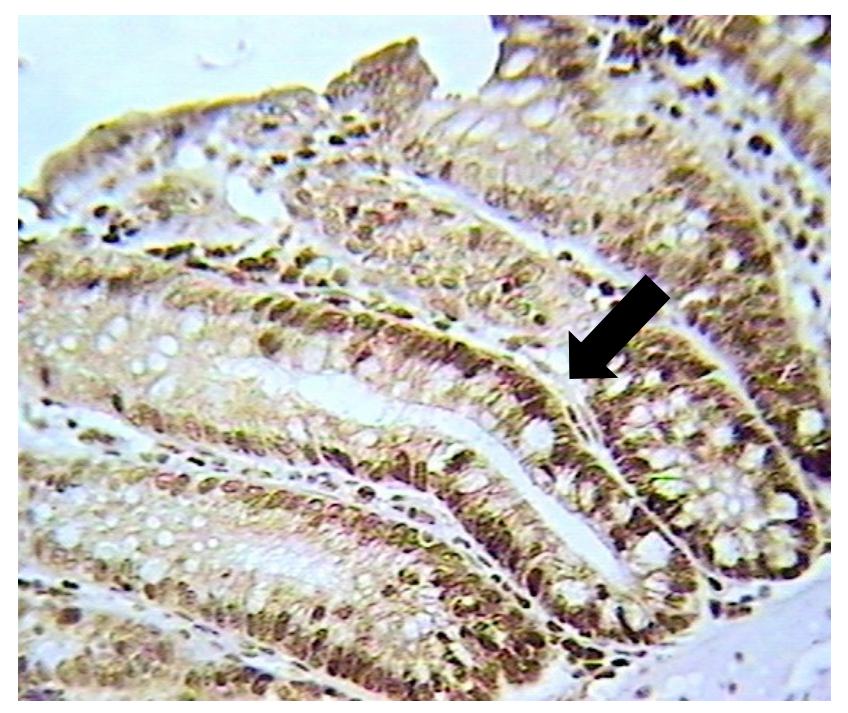

Figura 11. Marcação imunoistoquímica de PCNA

Os resultados de iPCNA são mostrados no gráfico 3. Uma dieta rica em gordura e Orlistat causaram um aumento no iPCNA, quando comparados ao grupo controle. Ambos, a dieta rica em gordura e Orlistat, causaram um aumento adicional no iPCNA nos animais tratados com o DMH. Nesses animais, a associação de uma dieta rica em gordura e Orlistat produza um efeito acumulativo do iPCNA, quando comparada a Orlistat sozinho. 


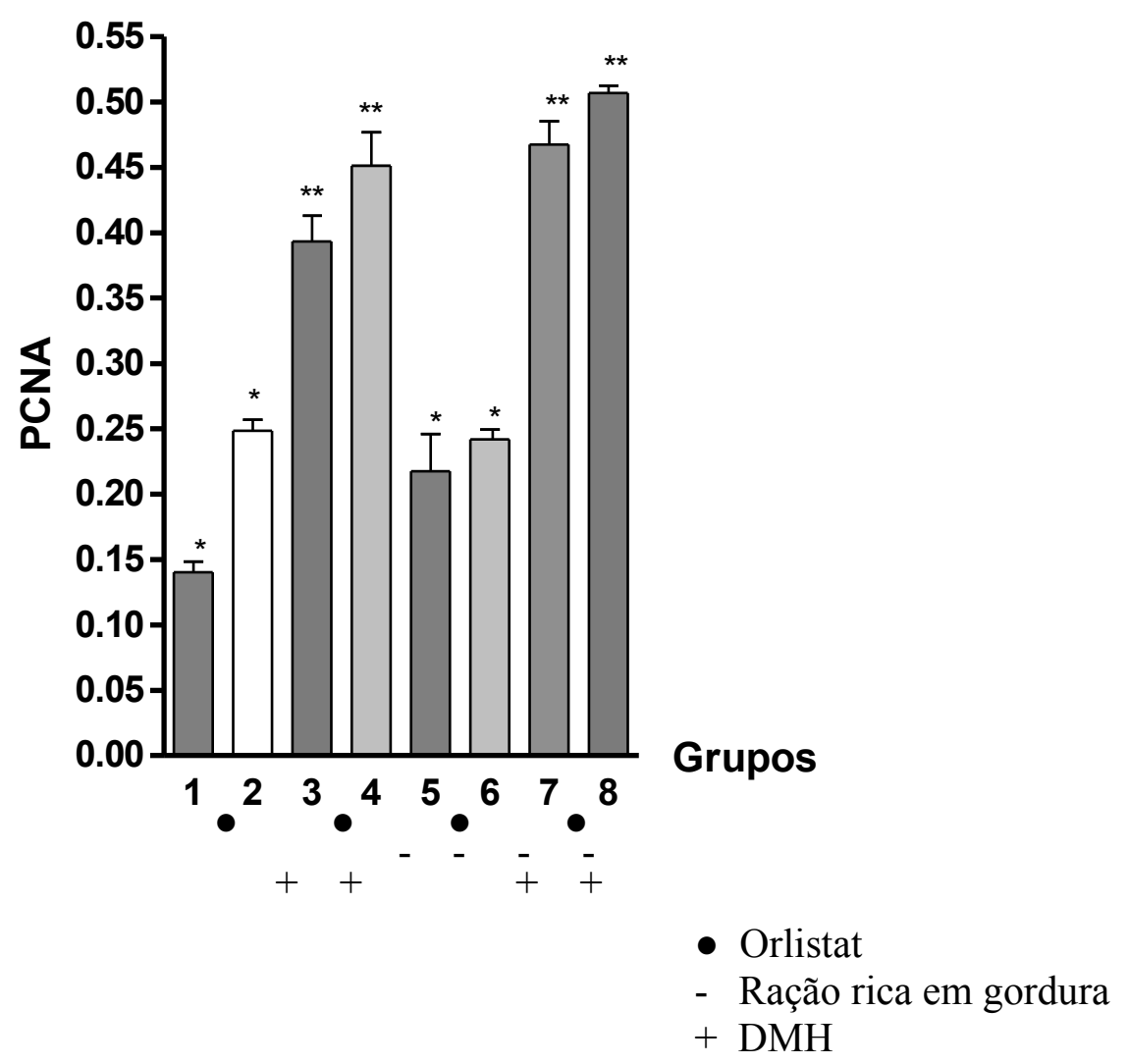

Gráfico 3 - Antígeno Nuclear de Proliferação Celular (PCNA) caracterizando o índice da mucosa colônica de rato.

Os ratos dos grupos 1 a 4 receberam ração Purina de rato.

Os grupos de 5 a 8 foram alimentados com ração rica em gordura.

Nos grupos 3, 4, 7 e 8 foram injetadas 2 doses do carcinógeno Dimetilhidrazina $(25 \mathrm{mg} / \mathrm{Kg})$, sendo 1 dose na primeira semana e outra na segunda.

Os grupos 2, 4, 6 e 8 foram alimentados com uma dieta suplementada com Orlistat (200mg/kg ração).

$* 1<2=5=6(p \leq 0,05)$

${ }^{* *} 3=4=7=8(p \leq 0,05)$ 
6. Discussão 
Nossos resultados confirmam a suposição de que o índice elevado de gordura no cólon distal pode aumentar o risco para o desenvolvimento do câncer colônico. Isso está do acordo com a literatura (MOROTOMI et al., 1997; NEWMARK et al., 2001; THORNTON \& MACDONALD, 1997).

Foi observado também que o uso de Orlistat aumenta os marcadores colônicos pré-neoplasicos na mesma proporção que uma dieta rica em gordura, sendo que os grupos 4 e 7 apresentaram resultados similares. Além disso, notou-se um efeito somatório de uma dieta rica em gordura e do Orlistat nos marcadores colônicos préneoplásicos, pois o grupo 8 apresentou número mais elevado de FCAs e iPCNA.

Os efeitos adversos gastrintestinais de Orlistat relacionados a um índice de gordura elevada no cólon são mais intensos, especialmente entre os pacientes que não aderem à dieta hipogordurosa recomendada (BAYS \& DUJOVNE, 2002).

Baseado somente nos resultados de nossa experiência, não podemos fazer indicações definitivas sobre os mecanismos e fatores envolvidos na pesquisa. Os mecanismos envolvidos na promoção do tumor de cólon em uma dieta rica em gordura não são conhecidos inteiramente. Propôs-se que a gordura da dieta induz mudanças na composição da membrana celular lipídica e a proliferação colônica o que pode ser relacionado ao desenvolvimento dos tumores (THORNTON \& MACDONALD, 1997). Os radicais livres podem ser envolvidos nestas mudanças, desde que uma dieta rica em gordura aumente a formação in vitro de uma espécie reativa de oxigênio nas fezes (ERHARDT et al., 1997). Os produtos da peroxidação lipídica, em particular radicais livres, estimulam a proliferação da síntese do DNA no epitélio colônico (BULL et al., 1984). Além disso, os radicais livres têm um papel permissivo para a carcinogênese e formação de radical livre intracolônico, sendo proposto para explicar as correlações 
observadas entre o excesso da gordura na dieta e uma incidência elevada do CCR (SALIM, 1993).

Talvez o dano biológico mais bem caracterizado causado pelos oxiradicais seja a sua habilidade de estimular a reação em cadeia dos radicais livres, conhecida como peroxidação lipídica. Esse fato ocorre quando a produção excessiva de radicais hidroxil próxima às membranas celulares capacita o ataque de ácidos graxos na membrana fosfolipídica, produzindo hidroxiperóxidos lipídicos (HALLIWELL \& GUTTERIDGE, 1989). O acúmulo desses agentes na membrana promove um dano oxidativo, assim reduzindo a fluidez e a permeabilidade da membrana, inativando sua função e causando seu colapso. Além do mais, os hidroxiperóxidos lipídicos podem decompor-se para fornecer uma variedade de produtos altamente citotóxicos, como os aldeídos (HALLIWELL \& GUTTERIDGE, 1989), podendo potencializar o dano tecidual. Tal dano pode ser um pré-requisito essencial para capacitar os carcinógenos a iniciar os processos neoplásicos.

Em um estudo realizado por Salim (1993) demonstrou que tecidos continuamente expostos a doses de carcinógenos são incapazes de produzir tumores, até que um fator não carcinogênico danifique o mecanismo de crescimento celular situado nas membranas celulares. Tal fator pode ser representado por radicais livres derivados de oxigênio, os quais atacam as membranas celulares e iniciam a peroxidação lipídica danificando os fatores de crescimento e permitindo que a carcinogênese seja provocada. Conseqüentemente, pode ser demonstrado que o papel da dieta gordurosa em promoção da carcinogênese colônica é mediado por radicais livres derivados de oxigênio, que exercem um papel permissivo na etiologia desse câncer. 
A descoberta de que radicais hidroxil altamente reativos podem ser produzidos abundantemente pelas fezes sob condições aeróbicas levam à hipótese de que radicais livres derivados de oxigênio gerados no material fecal próximo ao epitélio colônico podem ter um papel significante na etiologia do câncer colônico (BABBS, 1990).

Acredita-se que grande parte dos cânceres está fortemente relacionada ao ambiente externo. Desde a década de 1960, grande atenção vem sendo dada ao papel da dieta na gênese do câncer. Assim, alterações ocorridas na incidência dos cânceres de estômago, cólon, reto, bexiga, ovário e endométrio parecem ter sido influenciadas por modificações nos padrões alimentares (DOLL, 1992). Fatores casuais podem agir em conjunto ou em conseqüência para iniciar ou remover o processo da carcinogênese. Em geral, o processo ocorre lentamente, podendo levar anos entre exposições ou mutações, proliferação das células e detecção do câncer (Brasil. Ministério da Saúde, 2000).

Por outro lado, observou-se que o Orlistat interrompe a proliferação colônica do tumor, induz apoptose nas células tumorais e inibe o crescimento dos tumores nos ratos nude, possivelmente porque Orlistat é um inibidor da síntese do ácido graxo, uma enzima ligada fortemente à progressão do tumor (KRIDEL et al., 2004). Entretanto, deve-se considerar que também se observou que Orlistat não tem os mesmos efeitos nas células normais (KRIDEL et al., 2004). Em nosso modelo experimental, nós avaliamos somente as lesões pré-neoplásicas na mucosa colônica e é muito provável que esse possa explicar porque não foi encontrado nenhum efeito antiproliferativo do Orlistat.

Propôs-se que é necessário esclarecer não somente o impacto a longo prazo do tratamento com Orlistat, mas também descobrir o impacto a longo prazo na mortalidade 
e na morbidade (PADWAL et al., 2003). Nossos estudos sugerem que são necessárias mais pesquisas para melhorar a compreensão da conseqüência do aumento da gordura fecal causado pelo Orlistat na mucosa colônica para o uso seguro do Orlistat nos Seres humanos. 
7. CONCLUSÕES 
1. O potencial carcinogênico, em termos de formação de Focos de Criptas Aberrantes e de resposta proliferativa celular, decorrentes da administração de $\mathrm{DMH}$, foi aumentado pelo uso do Orlistat, de modo análogo ao que foi observado com o uso da dieta hipergordurosa.

2. Houve efeito somatório na formação de biomarcadores de carcinogênese colônica quando se associou o uso de Orlistat com dieta hipergordurosa 
8. REFERÊNCIAS BIBLIOGRÁFICAS 
ACKROFF, K; SCLAFANI, A. Effects of the lipase inhibitor Orlistat on intake and preference for dietary fat in rats. Am. J. Physiol., v. 271, p. 48-54, 1996.

AMERICAN CANCER SOCIETY. Cancer facts \& figures 2003. American Cancer Society, Atlanta, http://www.cancer.org/docroot/ home/index.asp, p. 41, 2003.

AMES, B.N; GOLD, L.S. Chemical carcinogenesis: too many rodent carcinogens. Proc. Natl. Acad. Sci., v. 878, n. 19, p. 7772-7776, 1990.

AMES, B.N; GOLD, L.S; WILLETT, W.C. The causes and prevention of cancer. Proc. Natl. Acad. Sci., v. 92, n.12, p. 5258-5265, 1995.

ANDERSON, D. Mechanisms of mutagenicity and tumor formation. In: Arinç, E.; Schenkman, JB.; Hodgson, E. Molecular Aspects of Oxidative drug metabolizing enzymes: their significance in environmental toxicology, chemical carcinogenesis and health. Springer-Verlag Berlin Heidelberg - NATO ASI Series, v. 90, p. 261-302, 1995.

BABBS, C.F. Free radicals and the etiology of colon cancer. Free Radic. Biol. Med., v. 8, n. 2, p. 191-200, 1990.

BAYS, H; DUJOVNE, C. Pharmacotherapy of obesity: currently marketed and upcoming agents. Am. J. Cardiovasc. Drugs., v. 2, n. 4, p. 245-253, 2002. 
BERTRAM, J.S; KOLONEL, L.N; MEYSKENS, F.L. Rational and strategies for chemoprevention of cancer in humans. Cancer Res., v. 47, n. 11, p. 3012-3031, 1987.

BIRD, R.P. Observation and quantification of aberrant crypts in the murine colon treated with a colon carcinogen: Preliminary findings. Cancer Lett., v. 37, n. 2, p. 147-151, 1987.

BIRD, R.P. Role of Aberrant crypt foci in understanding the pathogenesis of colon cancer. Cancer Lett., v. 93, n. 1, p. 55-71, 1995.

BULL, A.W; NIGRO, N.D; GOLEMBIESKI, W.A; CRISSMAN, J.D; MARNETT, L.J. In vivo stimulation of DNA synthesis and induction of ornithine decarboxylase in rat colon by fatty acid hydroperoxides, autoxidation products of unsaturated fatty acids. Cancer Res., v. 44, n. 11, p. 4924-4928, 1984.

DESCHNER, E.E. Experimentally Induced Cancer of the Colon. Cancer., v. 34, n. 3, p. 824-828, 1974.

DOLL, R. The lessons of life: Keynote address of the nutrition and cancer conference. Cancer Res., v. 52, n. 7, p. 2024s-2029s, 1992.

DOLL, R; PETO, R. The causes of cancer: quantitative estimates of avoidable risks of cancer in the United States today. J. Natl. Cancer Inst., v. 66, n. 6, p. 1191-1308, 1981. 
DRAGAN, Y; TEEGUARDEN, J; CANPBELL, H; HSIA, S; PITOT, $\mathrm{H}$. The quantitation of altered hepatic foci during multistage hepatocarcinogenesis en the rat: transforming growth factor ALFA espression as a marker for the stage of progression. Cancer Lett., v. 93 , n. 1, p. 73-83, 1995.

DUKES, C.F. The classification of cancer of the rectum. J. Pathol. Bacteriol., v. 35, p. 323-32, 1932.

ERHARDT, J.G; LIM, S.S; BODE, J.C; BODE, C. A diet rich in fat and poor in dietary fiber increases the in vitro formation of reactive oxigen species in human feces. J. Nutr., v. 127 n. 5, p. 706-709, 1997.

FARBER, E. Cell proliferation as a major risk factor for cancer: a concept of doubtful validity. Cancer Res., v. 55, n. 17, p. 3759-3762, 1995.

FARBER, E; RUBIN, H. Cellula adaptation in the origin and development of cancer. Cancer Res., v. 51, n. 11,p. 2751-2761, 1991.

FARBER, E and SARMA, D.S.R. Hepatocarcinogenesis: a dinamic cellular perspective. Lab. Invest., v. 56 n.1, p. 4-22, 1987.

FEARON, E.R. and VOGELSTEIN, B. A genetic model for colorectal tumorigenesis. Cell., v. 61, n. 5, p. 759-767, 1990. 
FODDE, R. The APC gene in colorectal cancer, Eur. J. Câncer, v. 38, n. 7, p. 867-871, 2002.

FRANKS, L.M. Introdução à Biologia Celular e Molecular do Câncer. Trad; revisão e organização de MM Brentani e R Chamas. São Paulo: Livraria Roca; O que é câncer? p. 1-22, 1990.

GETER, D.R; GEORGE, M.H; MOORE, T.M; KILBURN, S.R; $\underline{\text { HUGGINS-CLARK, G; }}$

DEANGELO, A.B. The effects of a high animal fat diet on the induction of aberrant crypt foci in the colons of male $\mathrm{F} 344 / \mathrm{N}$ rats exposed to trihalomethanes in the drinking water, Toxicol. Lett., v. 147, n. 3, p. 245-252, 2004.

GUERCIOLINI, R. Mode of action of Orlistat, Int. J. Obes. Relat. Metab. Disord., v. 3 p. S12-23, 1997.

HAFKAMP, A.M; $\underline{\text { HAVINGA, R; SINAASAPPEL,M; }}$ VERKADE, J. Effective oral treatment of unconjugated hyperbilirubinemia in Gunn rats, Hepatol., v. 41, n. 3, p. 526-34, 2005.

HALL, P.A. and COATES, P.J. Assessment of cellular proliferation in pathology _ What next? Histopathol., v. 26, n. 2 p.105-112, 1995.

HALL, P.A; LEVISON, D.A; WOODS, A.L; YU, C.C; KELLOCK, D.B. Proliferating cell nuclear antigen (PCNA) immunolocalization in parafin section: index of cell proliferation 
with evidence of deregulated expression in some neoplasms. The J. of Pathol., v.162, n. 4, p. 258-94, 1990.

HALLIWELL, B and GUTTERIDGE, J.M.C. Free radicals in biology and medicine. Clarendon., Oxford $2^{\text {nd }}$ ed, 1989.

HANIF, M.W; KUMAR, S. Pharmacological management of obesity. Expert pin Pharmacother., v.3, n. 12, p. 1711-1718, 2002.

HARRIS, C.C. Chemical and physical carcinogenesis: advances and perspectives for the 1990's. Cancer Res., v.18, n. 51, p. 5023-5044, 1991.

HSU, S.M; RAINE, L \& FANGER, H. Use of avidin-biotin-peroxidase complex (ABC) in imunoperoxidase techniques: comparison between $A B C$ and unlabeled antibody (PAP) procedures. J Histochem Cytochem., v. 29, n. 4, p. 577-589, 1981.

ISHIKAWA, T; TAKAYAMA, S; KITAGAWA, T. Correlation between time of partial hepatectomy after a single treatment with diethylnitrosamine and induction of adenosine triphosphatase-deficient islands in rat liver. Cancer Res., v. 40 n. 11, p. 4261-4264, 1980.

KNIGHT, J.A. Diseases related to oxygen-derived free radicals. Ann. Clin. Lab. Sci., v. 25, n. 2 p. 111-121, 1995. 
KRIDEL, S.J; AXELROD, F; ROZENKRANTZ, N; SMITH, J.W. Orlistat is a novel inhibitor of fatty acid synthase with antitumor activity. Cancer Res., v. 64 , n. 6, p. 20702075, 2004.

KURKI, P; VANDERLAAN, M; DOLBEARE, F; GRAY, J; TAN, E.M. Expression of proliferating cell nuclear (PCNA)/ cyclin during cell cycle. Exp. Cell. Res., v. 166, n. 10, p. 209-219, 1986.

KUSHI, L; GIOVANNUCCI, E. Dietary fat and cancer. Am. J. Med., v. 113, n. 19, p. 63S70S, 2002.

LAMONT, J.T; O'GORMAN, T.A. Experimental Colon Cancer. Gastroenterol., v. 75, n. 6, p.1157-1169, 1978.

LAU, G; CHAN, C.L. Massive hepatocellular [correction of hepatocellular] necrosis: was it caused by orlistat? Med. Sci. Law., v. 42, n. 4, p.309-312, 2002.

LOEB, L.A. Endogenous carcinigenesis: molecular oncology into the twenty-first century-presidential adress. Cancer Res., v. 49, n. 20, p. 5489-5496, 1989.

MARKS F, FURSTENBERGER G. Cancer chemoprevention through interruption of multistage carcinogenesis. The lessons learnt by comparing mouse skin carcinogenesis and human large bowel cancer. Eur. J. Cancer, v. 36, n. 3, p. 314-29, 2000. 
MCLELLAN, E.A; MEDLINE, A; BIRD, R.P. Dose response and proliferative characteristics of aberrant crypt foci: putative preneoplastic lesions in rat colon. Carcinogenesis, v. 12, n. 11, p. 2093-2098, 1991.

MCMORMICK, D; HALL, P.A. The complexities of proliferating cell nuclear antigen. Histopathol., v. 21, n. 6, p. 591-594, 1992.

MINISTÉRIO DA SAÚDE - BRASIL. INCA, Instituto Nacional de Câncer. Secretaria de Vigilância em Saúde. Secretaria de Atenção à Saúde. Coordenação de Prevenção e Vigilância. Estimativa 2006: Incidência de Câncer no Brasil. Disponível em: http://www.inca.org.br.

MINISTÉRIO DA SAÚDE - BRASIL. INCA, Instituto Nacional do Câncer. Secretaria Nacional de Assistência à Saúde."Estimativa da incidência e mortalidade por câncer no Brasil. Rio de Janeiro, MS/INCA, 2000.

MOROTOMI, M; SAKAITANI, Y; SATOU, M; TAKAHASHI, T; TAKAGI, A; ONOUE, M . Effects of a high-fat diet on azoxymethane-induced aberrant crypt foci and fecal biochemistry and microbial activity in rats. Nutr. Cancer, v. 27, n. 1, p. 84-91, 1997.

MURAKAMI, M.S; STROBEL, M.C; VANDE VOUDE, G.F. Cell cycle regulation, oncogenes, and antineoplastic drugs. In: Mendelsohn J, Howley, PM; Israel, MA; Liotta, LA. Eds The Molecular Basis of Cancer. Philadelphia: WB Saunders., p. 3-17, 1995. 
NEMETH, A; NADASI, E; GYONGYI, Z; OLASZ, L; NYARADY, Z; EMBER, A; KVARDA,A; BUJDOSO,L; ARANY,I; KISS,I; CSEJTEY,I; EMBER,I. Early effects of different cytostatic protocols for head and neck cancer on oncogene activation in animal experiments. Anticancer Res., v. 23, n. 6c, p. 4831-4835, 2003.

NEWMARK, H.L; YANG, K; LIPKIN, M; KOPELOVICH, L; LIU, Y; FAN, K; SHINOZAKI, H. A Western-style diet induces benign and malignant neoplasms in the colon of normal C57BI/6 mice. Carcinogenesis, v. 22, n. 11, p. 1871-1875, 2001.

OKADA, H; MIZUNO, M; IKEDA, N; TOMADA, J; TSUJI, T. Epithelial cell proliferation during colonic chemical carcinogenesis in the rat. J. Gastroenterol Hepatol., v. 11, n. 7 , p. 686-691, 1996.

OLIVEIRA, E.C; LEITE, M.S.B; MIRANDA, J.A.R; ANDRADE, A.L.S.S; GARCIA, S.B; LUQUETTI, A.O; MOREIRA, H. Chronic Trypanosoma cruzi infection associated with low incidence of 1,2-dimethylhydrazine-induced colon cancer in rats. Carcinogenesis, v. 22, n.5, p. 737-740, 2001.

PACKARD, K.A; WURDEMAN, R.L; REYES, A.P. Constipation, polyuria, polydipsia, and edema associated with Orlistat. Ann Pharmacother., v. 36, n. 7, p. 1168-1170, 2002. 
PADWAL, R; LI, S.K; LAU, D.C. Long-term pharmacotherapy for overweight and obesity: a systematic review and meta-analysis of randomized controlled trials. Int. J. Obes. Relat. Metab. Disord., v. 27, p. 1437-1446, 2003.

PARK, H.S; GOODLAD, R.A; WRIGHT, N.A. The incidence of Aberrant crypt foci and colonic Carcinoma in Dimethylhydrazine-treated Rats varies in a site-specific manner and depends on tumor histology. Cancer Res., v. 57, n.20, p. 4507-4510, 1997.

PITOT, H.C. The molecular biology carcinogenesis. Cancer., v. 72, n.3, p. 962-970, 1993.

PITOT, H.C. Progression: th terminal stage in carcinogenesis. Jpn. J. Cancer Res., v. 80 , n. 7, p. $559-607,1989$.

PITOT, H.C; DRAGAN, Y.P; TEEGUARDEN, J; HSIA, S; CAMPBELL, H. Quantitation of multistage carcinogenesis in rat liver. Toxicol. Pathol., v. 24, n. 1, p. 119-128, 1996.

PIVA-DEMARZO, M.M. \& GARCIA, S.B. Exhaustive physical exercise increases the number of colonic preneoplastic lesions in untrained rats treated with a chemical carcinogen. Cancer Lett., v. 216, p. 31-34, 2004.

QUINN, C.M; WRIGHT, N.A. The clinical assessment of proliferation and growth in human tumors: evaluation of methods and applications as prognostic variables. J. Pathol., v. 160, n. 2 p. 93-102, 1990. 
RAO, C.V; HIDROSE, Y; INDRANIE, C; REDDY, B.S. Modulation of experimental colon tumorigenesis by types and amounts of dietary fatty acids. Cancer Res., v. 61, n. 5, p. 1927-1933, 2001.

REDDY, B.S. Dietary fat and its relationship to large bowel cancer. Cancer Res., v. 41, p. $3700-3705,1981$.

REDDY BS, NARISAWA T, WRIGHT P, VUKUSICH D, WEISBURGER JH, WYNDER EL. Colon Carcinogenesis with azoximetane and dimethylhydrazine in germ free rats. Cancer Res., v. 35, n. 2 p. 287-290, 1975.

ROGERS, A.E; NAUSS, K.M. Rodent models for carcinoma of the colon. Dig. Dis. Sci., v. 30, n. 12, p. $87 s-102 s, 1985$.

ROSE, D.P; BOYAR, A.P; WYNDER, E.L. International comparison of mortality rates for cancer of the breast, ovary, prostate, and colon, and per capita food consumption. Cancer, v. 58, p. 2363-2371, 1986.

ROSEMBERG, D.W; LIU, Y. Induction of aberrant crypts in murine colon with varying sensivity ro colon carcinogenesis. Cancer Lett., v. 92 n. 2, p. 209-214, 1995. 
bSALIM, A.S. The permissive role of oxygen-derived free radicals in the development of colonic cancer in the rat. A new theory for carcinogenesis. Int. J. Cancer, v. 53, n. 6, p. 1031-1035, 1993.

SHIVAPURKAR, N.; HUANG, L.; SWALSKY, P.A; BAKKER, A; FINKELSTEIN, S; FROST, A; SILVERBERG, S. K-ras and p53 mutations in aberrant crypt foci and colonic tumors fron colon cancer patients. Cancer Lett., v. 115, n. 1, p. 39-46, 1997.

SHPITZ, B; BOMSTEIN, Y; MEKORI, Y; COHEN, R; KAUFMAN, Z; GRANKIN, M; BERNHEIM, J. Proliferating cell nuclear antigen as a marker of cell kinetics in aberrant crypt foci, hyperplastic polyps, adenomas, and adenocarcinomas of the human colon. Am. J. Surg., v. 174, n. 4, p. 425-30, 1997.

SINGH, J; RIVENSON, A; TOMITA, M; SHIMAMURA, S; ISHIBASHI, N; REDDY, B.S. Bifidobacterium longum, a lactic acid-producing intestinal bacterium inhibits colon cancer and modulates the intermediate biomarkers of colon carcinogenesis. Carcinogenesis, v. 18, n. 4, p. 833-841, 1997.

SIU, I.M; PRETLOW, T.G; AMINI, S.B; PRETLOW, T.P. Identification of Dysplasia in Human Colonic Aberrant Crypt Foci. Am. J. Pathol., v. 150, n. 5, p. 1805-1813, 1997.

THORNTON, W.H.Jr; MACDONALD, R.S. Dietary fat quantity and composition induce changes in proliferation and membrane lipids in rat colon cells. Ann. Nutr. Metab., v. 41, n. 4, p. 260-268, 1997. 
THORUP, I; MEYER, O; KRISTIANSEN, E. Influence of a dietary fiber on development of dimethylhydrazine-induced aberrant crypt foci and colon tumor incidence in Wistar rats, Nutr Cancer., v. 21, n. 2, p. 177-182, 1994.

TOMATIS, L. Cell proliferation and carcinogenesis: a brief history and current view based on na IARC workshop report. International Agency for Research on Cancer. Environ. Health Perspect., v. 101, n. 5, p. 149-151, 1993.

TSUJI, T; MIMURA, Y; WEN, S; LI, X; KANEKAWA, A; SASAKY, K; SHINOZAKI, F. The significance of PCNA and p53 protein in some oral tumors Int. J. Oral Maxillofac. Surg., v. 24, n. 3, p. 221-225, 1995.

VENNIT, S. Mechanisms of carcinogenesis and individual susceptibility to cancer. Clin. Chem., v. 40, n.7, p. 1421-1425, 1994.

VERMEULEN, K; VAN BOCKSTAELE, D.R; BERNEMAN, Z.N. The cell cycle: a review of regulation, deregulation and therapeutic targets in cancer. Cell Prolif., v. 36, n. 3, p. 131-149, 2003.

WYNDER, E; GORI, G. Contribution of the environment to cancer incidence - an epidemiological exercise. J. Natl. Cancer Inst., v. 58, n. 4, p. 825-832, 1977. 
YONISH-ROUACH, E; RESNITZKY, D; LOTEM, J; SACHS, L; KIMCHI, A; OREN, M. Wild-type p53 induces apoptosis of myeloid leukemic cells that is inhibiteted by interleukin-6. Nature, v. 352, n. 6333, p. 345-347, 1991.

YU, C.C.W; WOODS, A.L; LEVISON, D.A. The assessment of cellular proliferation by immunohistochemistry: a review of currently available methods and their application. Histochem. J., v. 24, n. 3, p. 121-131, 1992.

ZHI, J; MELIA, A.T; FUNK, C; VIGER-CHOUGNET, A; HOPFGARTNER, G; LAUSECKER, B; WANG, K; FULTON, J.S; GABRIEL, L; MULLIGAN, T.E. Metabolic profiles of minimally absorbed orlistat in obese/over-weight volunteers. J. Clin. Pharmacol., v. 36, n. 11, p. 1006-1011, 1996. 